\title{
A Phase I and Pharmacokinetic Study of Weekly Paclitaxel and Carboplatin in Patients with Metastatic Esophageal Cancer
}

\author{
Marco B. Polee, ${ }^{1}$ Alex Sparreboom, ${ }^{2}$ \\ Ferry A.L.M. Eskens, ${ }^{1}$ Ronald Hoekstra, ${ }^{1}$ \\ Jacqueline van de Schaaf, 'Jaap Verweij, ${ }^{1}$ \\ Gerrit Stoter, ${ }^{1}$ and Ate van der Gaast ${ }^{1}$ \\ Erasmus Medical Center, Department of ${ }^{1}$ Medical Oncology and \\ ${ }^{2}$ Laboratory of Translational and Molecular Pharmacology, \\ Rotterdam, the Netherlands
}

\section{ABSTRACT}

Purpose: To determine the maximum-tolerated dose, toxicity profile, and pharmacokinetics of a fixed dose of paclitaxel followed by increasing doses of carboplatin, given weekly to patients with advanced esophageal or gastric junction cancer.

Experimental Design: Paclitaxel was administered on day 1 as a 1-h infusion at a fixed dose of $100 \mathrm{mg} / \mathrm{m}^{2}$ followed by a 1-h infusion of carboplatin targeting an area under the curve (AUC) of $2-5 \mathrm{mg} \times \mathrm{min} / \mathrm{ml}$, with cycles repeated on days $8,15,29,36$, and 43 .

Results: Forty patients [36 males; median (range) age, 57 (40-74) years] were enrolled. Dose-limiting toxicity was observed at a carboplatin AUC of $5 \mathrm{mg} \times \mathrm{min} / \mathrm{ml}$ and consisted of treatment delay attributable to myelosuppression. No grade 3/4 treatment-related nonhematological toxicity was observed. The highest dose intensity ( $>95 \%$ of the planned dose over time) was achieved with a carboplatin AUC of $4 \mathrm{mg} \times \mathrm{min} / \mathrm{ml}$. The mean $( \pm \mathrm{SD})$ AUCs of unbound $(\mathrm{Cu})$ and total paclitaxel were $0.662 \pm 0.186$ and $7.37 \pm 1.33$ $\mu \mathrm{M} \times \mathrm{h}$, respectively. Clearance of $\mathrm{Cu}$ was $188 \pm 44.6$ liter $/ \mathrm{h} / \mathrm{m}^{2}$, which is not significantly different from historical data $(P=0.52)$. Cremophor $E L$ clearance was $123 \pm 23$ $\mathrm{ml} / \mathrm{h} / \mathrm{m}^{2}$, similar to previous findings. Of 37 patients evaluable for response, 1 had complete response, 19 had partial response, and 10 had stable disease, accounting for an overall response rate of $54 \%$.

Conclusions: This regimen is very tolerable and effective, and the recommended doses for additional studies are paclitaxel $\left(100 \mathrm{mg} / \mathrm{m}^{2}\right)$, with carboplatin targeting an AUC of $4 \mathrm{mg} \times \mathrm{min} / \mathrm{ml}$.

Received 9/30/03; revised 12/12/03; accepted 12/23/03.

Grant support: Bristol-Myers Squibb grant.

The costs of publication of this article were defrayed in part by the payment of page charges. This article must therefore be hereby marked advertisement in accordance with 18 U.S.C. Section 1734 solely to indicate this fact.

Requests for reprints: Ate van der Gaast, Department of Medical Oncology, Erasmus Medical Center, P. O. Box 2040, the Netherlands. E-mail: a.vandergaast@erasmusmc.nl.

\section{INTRODUCTION}

Esophageal cancer is among the 10 most frequently occurring human malignancies in the world. Although the incidence of squamous cell cancer remains relatively constant, the incidence of adenocarcinoma of the distal esophagus or esophagealgastric junction is rapidly increasing in Western countries, including the United States (1). This rising incidence is not completely explained yet, but obesity, gastric reflux, and the development of an intestinalized columnar epithelium (Barrett's esophagus) in the squamous lining of the esophagus have been identified as important risk factors for development of adenocarcinomas in the distal esophagus (2-4). Approximately 50\% of the patients present with systemic disease and the majority of patients being treated for localized disease will develop metastatic disease with or without local recurrence after esophageal resection.

Cisplatin-based chemotherapy regimens are commonly used as preoperative treatment for patients with resectable disease or patients with advanced disease. In combination with 5-fluorouracil, response rates of 35\% in metastatic and $45-55 \%$ in locoregional disease have been reported (5). More recently, irinotecan and paclitaxel have been identified as new agents in the treatment of esophageal cancer. The response rate after treatment with irinotecan, administered weekly as a single agent, was $15 \%$ (6), and in combination with cisplatin, the response rate was $57 \%$ (7). Combination therapy of cisplatin and paclitaxel, either administered weekly, biweekly or every 3 weeks, in patients with advanced esophageal cancer has been evaluated previously, with response rates ranging from 42 to $52 \%(8-12)$. When paclitaxel was administered over $24 \mathrm{~h}$ in combination with cisplatin with or without 5-fluorouracil, the predominant toxicity was myelosuppression $(8,9)$. Myelotoxicity was less severe when paclitaxel was administered over $3 \mathrm{~h}$ in a weekly or biweekly schedule in combination with cisplatin, although the incidence and severity of sensory neurotoxicity increased (10-12).

Recently, the safety and efficacy of weekly administrations of paclitaxel in patients with breast, ovarian, and lung cancer have been reported (13-16). Doses of $100-175 \mathrm{mg} / \mathrm{m}^{2} /$ week are well tolerated with minimal hematological toxicity and reversible neurotoxicity (14). Furthermore, it is possible to combine weekly paclitaxel administration with carboplatin either in a weekly schedule at a dose to produce a target area under the plasma concentration time curve (AUC) of $2 \mathrm{mg} / \mathrm{ml} \times \min$ (AUC 2) or every 3 weeks at dose level targeting AUC 6 (17). On the basis of our favorable experience with dose-dense biweekly and weekly schedules of cisplatin and paclitaxel, we initiated a dose-finding study with a weekly schedule of a fixed dose of paclitaxel and escalating doses of carboplatin. The advantage of a paclitaxel-carboplatin regimen over a cisplatinpaclitaxel regimen is that it can be given as an outpatient treatment and probably induces less neurotoxicity. The objec- 
tives of this study were to assess the safety and toxicity of this combination and determine the dose-limiting toxicities (DLT), maximum-tolerated dose (MTD), and recommended dose for further evaluation.

\section{PATIENTS AND METHODS}

Eligibility. Patients with histological proven metastatic or unresectable adenocarcinoma, undifferentiated or squamous cell carcinoma of the esophagus or gastro-esophageal junction area were eligible for the study. Tumors invading adjacent structures (T4) or with proven distant metastases (M1a or M1b) were considered unresectable. Additional eligibility requirements included: (a) life expectancy of $>12$ weeks; $(b)$ age $\geq 18$ years; (c) WHO performance status $0-2$; adequate hematological (granulocytes $\geq 1.5 \times 10^{9} /$ liter and platelets $\geq 100 \times$ $10^{9} /$ liter); $(d)$ renal (serum creatinine $\leq 120 \mu \mathrm{mol} / \mathrm{liter}$ ); and $(e)$ hepatic functions (total bilirubin $\leq 1.5 \times$ upper normal limit). Patients with neurotoxicity graded $>1$ according to the National Cancer Institute Common Toxicity Criteria (CTC) version 2 were not eligible. Previous radiation for primary or metastatic disease was allowed but not in the 4 weeks before study entry and when not involving $>30 \%$ of the bone marrow. Patients treated previously with chemotherapy were not eligible. The study was approved by the Erasmus Medical Center ethics committee (Rotterdam, the Netherlands), and all patients provided written informed consent.

Pretreatment and Follow-Up. Before treatment, a complete medical history was taken, and physical examination, laboratory studies, electrocardiogram, and imaging studies for tumor measurements were performed. Laboratory studies included a complete blood cell count analysis with WBC differential, sodium, potassium, calcium, phosphorus, urea, creatinine, total protein, albumin, bilirubin, alkaline phosphatase, alanine aminotransferase, aspartate aminotransferase, and lactate dehydrogenase.

History, physical examination, and toxicity scoring according to National Cancer Institute CTC definitions were performed weekly. Blood cell counts and serum chemistry studies were also performed weekly. Tumor measurements were performed after six administrations by a computed tomography scan of the chest and upper abdomen. Patients with the primary tumor in situ were also evaluated by endoscopy. Standard WHO response criteria were used (18). Duration of response was calculated difinitions from the start of treatment.

Drug Administration. All patients received dexamethasone $(10 \mathrm{mg})$, clemastine $(2 \mathrm{mg})$, and ranitidine $(50 \mathrm{mg})$, administered i.v. $30 \mathrm{~min}$ before paclitaxel infusion. Patients received paclitaxel as a 1-h infusion diluted in $500 \mathrm{ml}$ of sterile and isotonic $(0.9 \%$, volume for volume) sodium chloride solution (saline), with the total drug dose normalized to a patient's body surface area. After the completion of the paclitaxel infusion, $100 \mathrm{ml}$ of saline were infused over $30 \mathrm{~min}$, followed by an infusion of ondansetron ( $8 \mathrm{mg}$ ) diluted in $100 \mathrm{ml}$ of saline given over $30 \mathrm{~min}$. Hereafter, the total calculated dose of carboplatin, diluted in $500 \mathrm{ml}$ of $5 \%$ (weight/volume) dextrose solution, was administered in $1 \mathrm{~h}$.

Study Design. Paclitaxel and carboplatin were administered on days $1,8,15,29,36$, and 43 . The paclitaxel dose was fixed at $100 \mathrm{mg} / \mathrm{m}^{2} /$ administration, and the starting dose of carboplatin was set at a targeted AUC of 2 according to a formula published previously (19). The creatinine clearance was estimated by the Cockcroft-Gault equation. The carboplatin dose was escalated per cohort in steps targeting an increase in AUC of $0.5 \mathrm{mg} / \mathrm{ml} \times \mathrm{min}$. In each cohort, 3 patients were treated until DLT was observed. If two or more DLTs were observed, that dose was considered too high. In the case of one DLT, the accrual of 3 additional patients was required. If DLT was seen in no more than 1 patient at that dose level, the dose was to be further escalated. The dose level at which $\geq 2$ patients experienced DLT was considered the MTD. The dose below MTD would be the recommended dose for additional studies. DLT was defined as any of the following events occurring during treatment: (a) grade 3-4 neutropenia with infection or fever requiring parenteral antibiotics; $(b)$ grade 3-4 thrombocytopenia requiring two or more platelet transfusions or resulting in more than or equal to grade 2 hemorrhage; $(c)$ nonhematological toxicity more than or equal to grade 3 with the exception of acute nausea and/or vomiting; and $(d)$ and/or dose reductions and/or treatment delay for $>1$ week for reasons of toxicity.

Patients were retreated on days 8 and 15 provided the WBC was $\geq 1 \times 10^{9} /$ liter and platelets were $\geq 50 \times 10^{9} /$ liter, whereas before the start of the day 29 course, the WBCs had to be $\geq 3 \times$ $10^{9} /$ liter and platelets $\geq 100 \times 10^{9} /$ liter. When these criteria were not met, treatment was postponed for 1 week. If bone marrow recovery was still insufficient after this week, patients were taken off study. Dose reduction was performed in patients with neutropenic fever or grade 3-4 thrombocytopenia requiring two or more platelet transfusions or resulting in more than or equal to grade 2 hemorrhage; in that case, patients were retreated at the preceding dose level. Responding patients could receive additional local therapy in case of limited lymph node metastasis or additional cycles of carboplatin and paxlitaxel in case of distant metastatic disease. These additional cycles could also be administered in a traditional 3-weekly schedule.

After establishing a recommended dose, 8 additional patients would be treated at this dose level. This was done to demonstrate the feasibility and to estimate the dose-intensity of this schedule. Pharmacokinetic analysis were performed in these patients.

Sampling Schedule and Drug Analysis. Blood volumes of $5 \mathrm{ml}$ were drawn directly into Vacutainer tubes containing lithium heparin (Becton Dickinson, Meylin, France) from a peripheral venous access device. Samples were collected at the following time points: $(a)$ immediately before paclitaxel treatment; (b) at $0.5 \mathrm{~h}$ after the start of infusion; (c) $5 \mathrm{~min}$ before the end of infusion; and $(d)$ at $0.5,1,3,7$, and $23 \mathrm{~h}$ after the end of infusion. After centrifugation at $2000 \times g$ for $5 \mathrm{~min}$, the plasma fraction was separated, transferred into a clean polypropylene tube, and stored frozen at $-20^{\circ} \mathrm{C}$ until analysis. Total concentrations of paclitaxel (i.e., the total of bound and unbound) in plasma were determined by a validated reversed phase highperformance liquid chromatographic assay with detection at a wavelength of $230 \mathrm{~nm}$, as described previously (20). This assay has a lower limit of quantitation of $10 \mathrm{ng} / \mathrm{ml}$, with an accuracy (i.e., percentage deviation from nominal concentrations) of $\pm 3 \%$. Unbound concentrations of paclitaxel in plasma were 
obtained from an equilibrium dialysis method using generally tritium-labeled paclitaxel as a tracer (21). The analytical procedure for Cremophor EL was based on a colorimetric dyebinding microassay using Coomassie-Brilliant Blue G-250 (BioRad Laboratories, Munchen, Germany), according to a published procedure (22). The lower limit of quantitation of this procedure was $0.5 \mu \mathrm{l} / \mathrm{ml}$, with an accuracy of $<6.5 \%$.

Pharmacokinetic Data Analysis. The fractions unbound (fu) paclitaxel in each individual patient plasma sample, including the blank, were determined after analysis for total radioactivity (i.e., $\left[{ }^{3} \mathrm{H}\right]$ paclitaxel) by liquid scintillation counting. The unbound drug concentrations $(\mathrm{Cu})$ were calculated from the fraction unbound drug (fu) and total drug concentration $(\mathrm{Cp}$; i.e., the total of unbound, protein bound and Cremophor EL associated), as $\mathrm{Cu}=\mathrm{fu} \times \mathrm{Cp}$. Estimates of pharmacokinetic parameters for unbound paclitaxel and total paclitaxel in plasma were derived from individual concentration time data sets by a linear multicompartmental analysis using the software package Siphar version 4.0 (InnaPhase, Philadelphia, PA). This program determines the slopes and intercepts of the logarithmically plotted curves of multiexponential functions using nonlinear least squares, iterative steps. Initial parameter estimates were determined by an automated curve-stripping procedure. The mathematical equations describing the drug concentration $\mathrm{C}_{(\mathrm{t})}$ at any time t during and after i.v. administration are given by $\mathrm{C}_{(\mathrm{t})}=\Sigma$ $\left[\mathrm{C}_{i} /\left(\lambda_{i} \times \mathrm{T}_{\mathrm{inf}}\right) \times\left(1-\mathrm{e}^{(-\lambda i \times \mathrm{t})}\right)\right]$ and $\mathrm{C}_{(\mathrm{t})}=\Sigma\left[\mathrm{C}_{i} /\left(\lambda_{i} \times \mathrm{T}_{\mathrm{inf}}\right) \times\right.$ $\left.\left(\mathrm{e}^{(-\lambda i \times[\mathrm{t}-\operatorname{Tinf}])}-\mathrm{e}^{(-\lambda i \times \mathrm{t})}\right)\right]$, respectively. In these equations, $\lambda_{i}$ is the component of the $i$-th exponential term, $\mathrm{C}_{i}$ is the initial concentration of the $i$-th component of the curve, and $\mathrm{T}_{\text {inf }}$ is the infusion duration. In all cases, paclitaxel concentration time curves were best described with a tri-exponential model, which gave the lowest Akaike information criterion, without any demonstration of saturable behavior $\left(R^{2}=0.996 \pm 0.002\right.$, root mean square error $=14 \pm 3.5 \%$ ). The curve fitting procedure with this model yields the parameters $\mathrm{C}_{1}, \mathrm{C}_{2}, \mathrm{C}_{3}, \lambda_{1}, \lambda_{2}$, and $\lambda_{3}$. The AUC values were determined on the basis of the parameters of the equations with extrapolation to infinity using the terminal disposition rate constant. The clearance was defined as dose (expressed in $\mu \mathrm{mol} / \mathrm{m}^{2}$ ) divided by AUC. The volume of distribution at steady state was calculated as the product of clearance and the mean residence time, also estimated from the equations. Peak plasma concentrations were put on par with observed (experimental) drug levels immediately after the end of infusion.

Estimates of pharmacokinetic parameters for Cremophor EL in plasma were derived from individual concentration time data sets by noncompartmental analysis using the software package WinNonLin version 3.0 (Pharsight Corp., Mountain View, CA). The peak plasma concentrations and time to peak were the observed values. The AUC was calculated using the log-linear trapezoidal method from time 0 to the time of the final quantifiable concentration [AUC(tf)]. The AUC was also extrapolated to infinity by dividing the last measured concentration by the rate constant of the terminal phase $(k)$, determined by linear regression analysis of the last three measurable concentrations $\left(R^{2}=0.983 \pm 0.021\right)$. The systemic clearance was calculated by dividing the administered dose (expressed in microliters) by the observed AUC(inf), and the terminal disposition half-life was calculated as $\ln (2) / k$.
All pharmacological parameters are expressed as mean values $\pm \mathrm{SD}$, unless stated otherwise. Interindividual variability in parameters was expressed as the coefficient of variation, calculated as the ratio of the SD and observed mean, and multiplied by 100 . The effect on the two different targeted carboplatin exposure levels (AUC of 4 and 4.5) on the generated data was evaluated statistically using a nonparametric Wilcoxon (two group) test. A comparative analysis with data obtained from patients receiving single-agent paclitaxel with those obtained in the current trial was performed using a nonparametric Kruskal-Wallis (multiple group) test. The level of significance was set at $P<0.05$. All statistical calculations were performed using JMP version 3.2.6 (SAS Institute, Inc., Cary, NC).

Pharmacodynamic analysis was not performed, because the number of patients that were analyzed was too small.

\section{RESULTS}

Patients and Toxicity Profiles. A total of 40 eligible patients entered the study. Patient characteristics are shown in Table 1 . Two patients had pulmonary embolism 2 weeks after start of treatment; both patients recovered and were able to complete treatment. As these patients had a treatment delay attributable to other reasons than chemotherapy-induced toxicity, they were considered not to be fully assessable for toxicity.

Table 1 Patient characteristics

\begin{tabular}{|c|c|c|}
\hline & $\begin{array}{c}\text { No. of } \\
\text { patients }\end{array}$ & $(\%)$ \\
\hline Total entered & 40 & \\
\hline \multicolumn{3}{|l|}{ Sex } \\
\hline Female & 4 & \\
\hline Male & 36 & \\
\hline \multicolumn{3}{|l|}{ Age, years } \\
\hline Median & 57 & \\
\hline Range & $40-74$ & \\
\hline \multicolumn{3}{|l|}{$\mathrm{ECOG}^{a}$ performance score } \\
\hline 0 & 19 & 48 \\
\hline 1 & 17 & 42 \\
\hline 2 & 4 & 10 \\
\hline \multicolumn{3}{|l|}{ Weight loss } \\
\hline $0-5 \%$ & 17 & 42 \\
\hline $5-10 \%$ & 14 & 36 \\
\hline$>10 \%$ & 9 & 23 \\
\hline \multicolumn{3}{|l|}{ Histology } \\
\hline Adenocarcinoma & 34 & 85 \\
\hline Squamous cell carcinoma & 5 & 13 \\
\hline Undifferentiated carcinoma & 1 & 3 \\
\hline \multicolumn{3}{|l|}{ Location primary tumor } \\
\hline Proximal esophagus & 1 & 3 \\
\hline Mid & 7 & 18 \\
\hline Distal & 19 & 48 \\
\hline Gastroesophageal junction & 13 & 33 \\
\hline \multicolumn{3}{|l|}{ Extent of disease } \\
\hline Locally advanced/unresectable & 0 & \\
\hline Primary with distant metastases & 30 & 75 \\
\hline Metastases after primary resection & 10 & 25 \\
\hline \multicolumn{3}{|l|}{ Metastatic sites } \\
\hline Lymph nodes only & 7 & 18 \\
\hline Liver & 18 & 45 \\
\hline Other & 15 & 38 \\
\hline
\end{tabular}

${ }^{a}$ ECOG, Eastern Cooperative Oncology Group. 
Table 2 Worst hematological toxicity per patient

\begin{tabular}{|c|c|c|c|c|c|c|c|c|c|c|c|c|c|c|c|c|}
\hline \multirow{2}{*}{$\begin{array}{l}\text { Carboplatin } \\
\text { dose level }\end{array}$} & \multirow{2}{*}{$\begin{array}{l}\text { No. of patients/no. } \\
\text { of administrations }\end{array}$} & \multicolumn{4}{|c|}{ Neutropenia $^{a}$} & \multicolumn{6}{|c|}{ Thrombocytopenia $^{a}$} & \multicolumn{5}{|c|}{ Anemia $^{a}$} \\
\hline & & 0 & 1 & 2 & 3 & 4 & 0 & 1 & 2 & 3 & 4 & 0 & 1 & 2 & 3 & 4 \\
\hline AUC $2^{b}$ & $3 / 18$ & 1 & 0 & 1 & 1 & 0 & 3 & 0 & 0 & 0 & 0 & 2 & 1 & 0 & 0 & 0 \\
\hline AUC 2.5 & $3 / 18$ & 0 & 1 & 1 & 1 & 0 & 2 & 1 & 0 & 0 & 0 & 0 & 3 & 0 & 0 & 0 \\
\hline AUC 3 & $3 / 18$ & 0 & 0 & 2 & 1 & 0 & 2 & 1 & 0 & 0 & 0 & 1 & 2 & 0 & 0 & 0 \\
\hline AUC 3.5 & $3 / 18$ & 0 & 0 & 0 & 2 & 1 & 2 & 1 & 0 & 0 & 0 & 1 & 2 & 0 & 0 & 0 \\
\hline AUC 4 & $12 / 68$ & 0 & 0 & 1 & 4 & 7 & 5 & 5 & 1 & 0 & 1 & 3 & 6 & 3 & 0 & 0 \\
\hline AUC 4.5 & $11 / 63$ & 0 & 1 & 2 & 5 & 3 & 3 & 4 & 3 & 1 & 0 & 4 & 3 & 4 & 0 & 0 \\
\hline AUC 5 & $2 / 12$ & 0 & 0 & 0 & 1 & 1 & 0 & 0 & 0 & 2 & 0 & 1 & 1 & 0 & 0 & 0 \\
\hline
\end{tabular}

${ }^{a}$ Graded according to National Cancer Institute common toxicity criteria.

${ }^{b}$ AUC, area under the plasma concentration time curve (in $\mathrm{mg} \times \mathrm{min} / \mathrm{ml}$ ).

One patient refused further treatment after two courses of chemotherapy.

The carboplatin dose was increased from the first dose level (AUC 2) to dose level AUC 5. At dose level AUC 4, 1 patient had DLT after three administrations, consisting of neutropenic fever and grade 3 diarrhea. She had to be admitted and recovered after treatment with i.v. broad spectrum antibiotics. At the dose level AUC 4.5, another patient had a DLT. This patient developed neutropenic fever after the third course of treatment and also recovered after antibiotic treatment. Both patients treated at carboplatin dose level AUC 5 had a treatment delay-related DLT. These 2 patients were not able to continue treatment at day 29, and treatment had to be delayed for 2 and 3 weeks, respectively, because of protracted myelosuppression; consequently, this dose level was considered to be the MTD. As per protocol, 8 patients were additionally treated at carboplatin level AUC 4.5, and pharmacokinetic analyses were performed. However, treatment delay frequently occurred at this dose level, and therefore, 6 additional patients were treated at carboplatin dose AUC 4. Pharmacokinetic analyses were also performed at this latter dose level.

Toxicity data are shown in Tables 2 and 3. Neutropenia grade 3 or 4 was observed in $25(77 \%)$ patients. The granulocyte nadir usually occurred after the fifth or sixth treatment course. Thrombocytopenia grade 3 or 4 was observed in 4 patients and occurred at carboplatin dose levels of AUC $\geq 4$. Nonhematological toxicity predominantly consisted of sensory neurotoxicity grade 1 or 2 occurring in $7(19 \%)$ and $2(5 \%)$ patients, respectively. Fatigue was observed in $24(65 \%)$ patients and did not appear to be dose related. Nephrotoxicity did not occur. Alopecia was universal.

A total of 215 administrations was given. Table 4 shows the achieved dose intensity and observed treatment delays. Thirteen $(6 \%)$ administrations were delayed in $11(30 \%)$ patients, and almost all delays occurred at day 29. Five administrations had to be delayed because of unresolved thrombocytopenia, one administration because of leucocytopenia, and five administrations because of both thrombocytopenia and leucocytopenia. One patient had two administrations delayed for 1 week because of fatigue. A treatment delay caused by myelotoxicity also was observed in 8 of 11 patients treated at carboplatin dose level AUC 4.5. Therefore, we considered carboplatin targeted at AUC 4 the recommended dose for weekly treatment in combination with paclitaxel administered at $100 \mathrm{mg} / \mathrm{m}^{2}$. Because at this dose level only 1 patient had a treatment delay of 1 week, we achieved the highest dose intensity for paclitaxel and carboplatin. The median dose intensity at dose level AUC 4 after six courses calculated over an 8 -week period was $75 \mathrm{mg} / \mathrm{m}^{2} /$ week for paclitaxel and AUC 3/week for carboplatin.

Drug Disposition. Pharmacokinetic analysis of unbound and total paclitaxel was performed during the first cycles of treatment in 14 patients treated at a carboplatin AUC of 4 or 4.5 (Table 5). A summary of the plasma pharmacokinetic parameters is presented in Table 6. Moderate interindividual variability in paclitaxel AUC was noted, both for the unbound fraction (i.e., $\sim 28 \%$ ) as well as for total drug (i.e., $\sim 18 \%$ ). The exposure to unbound paclitaxel was not significantly different in patients receiving either carboplatin targeted at an AUC of 4 or 4.5 , with

Table 3 Worst nonhematological toxicity per patient

\begin{tabular}{|c|c|c|c|c|c|c|c|c|c|c|c|c|c|c|c|c|c|c|c|c|c|c|c|c|c|c|}
\hline \multirow{2}{*}{$\begin{array}{l}\text { Carboplatin } \\
\text { dose level }\end{array}$} & \multirow{2}{*}{$\begin{array}{l}\text { No. of patients/no. } \\
\text { of administrations }\end{array}$} & \multicolumn{5}{|c|}{ Nausea $^{a}$} & \multicolumn{5}{|c|}{ Vomiting $^{a}$} & \multicolumn{5}{|c|}{ Neurotoxicity $^{a}$} & \multicolumn{5}{|c|}{ Diarrhea $^{a}$} & \multicolumn{5}{|c|}{ Fatigue $^{a}$} \\
\hline & & 0 & 1 & 2 & 3 & 4 & 0 & 1 & 2 & 3 & 4 & 0 & 1 & 2 & 3 & 4 & 0 & 1 & 2 & 3 & 4 & 0 & 1 & 2 & 3 & 4 \\
\hline $\mathrm{AUC} 2^{b}$ & $3 / 18$ & 2 & 0 & 1 & 0 & 0 & 2 & 0 & 1 & 0 & 0 & 3 & 0 & 0 & 0 & 0 & 2 & 0 & 1 & 0 & 0 & 0 & 1 & 2 & 0 & 0 \\
\hline AUC 2.5 & $3 / 18$ & 0 & 3 & 0 & 0 & 0 & 2 & 1 & 0 & 0 & 0 & 2 & 1 & 0 & 0 & 0 & 3 & 0 & 0 & 0 & 0 & 0 & 2 & 1 & 0 & 0 \\
\hline AUC 3 & $3 / 18$ & 1 & 2 & 0 & 0 & 0 & 3 & 0 & 0 & 0 & 0 & 3 & 0 & 0 & 0 & 0 & 2 & 1 & 0 & 0 & 0 & 1 & 1 & 1 & 0 & 0 \\
\hline AUC 3.5 & $3 / 18$ & 1 & 2 & 0 & 0 & 0 & 3 & 0 & 0 & 0 & 0 & 2 & 1 & 0 & 0 & 0 & 2 & 1 & 0 & 0 & 0 & 1 & 2 & 0 & 0 & 0 \\
\hline AUC 4 & $12 / 68$ & 5 & 5 & 2 & 0 & 0 & 9 & 3 & 0 & 0 & 0 & 8 & 3 & 1 & 0 & 0 & 5 & 4 & 2 & 1 & 0 & 4 & 4 & 4 & 0 & 0 \\
\hline AUC 4.5 & $11 / 63$ & 3 & 4 & 4 & 0 & 0 & 8 & 3 & 0 & 0 & 0 & 8 & 2 & 1 & 0 & 0 & 9 & 1 & 1 & 0 & 0 & 4 & 6 & 0 & 1 & 0 \\
\hline AUC 5 & $2 / 12$ & 1 & 1 & 0 & 0 & 0 & 2 & 0 & 0 & 0 & 0 & 1 & 1 & 0 & 0 & 0 & 1 & 1 & 0 & 0 & 0 & 1 & 1 & 0 & 0 & 0 \\
\hline
\end{tabular}

${ }^{a}$ Graded according to National Cancer Institute common toxicity criteria.

${ }^{b}$ AUC, area under the plasma concentration time curve $(\mathrm{mg} \times \mathrm{min} / \mathrm{ml})$. 
Table 4 Summary of treatment delays per dose level

\begin{tabular}{lccccc}
\hline $\begin{array}{c}\text { Carboplatin } \\
\text { dose level }\end{array}$ & $\begin{array}{c}\text { No. of patients/no. } \\
\text { of administrations }\end{array}$ & $\begin{array}{c}\text { No. of patients } \\
\text { with a delay }(\%)\end{array}$ & $\begin{array}{c}\text { No. of administrations } \\
\text { with a delay }(\%)\end{array}$ & $\begin{array}{c}\text { Total no. of } \\
\text { weeks delay }\end{array}$ & $\begin{array}{c}\text { Dose intensity carboplatin } \\
\text { (AUC/week) }\end{array}$ \\
\hline AUC 2 & $3 / 18$ & 0 & 0 & 0 & 1.5 \\
AUC 2.5 & $3 / 18$ & 0 & 0 & 0 & 1.9 \\
AUC 3 & $3 / 18$ & 0 & 0 & 0 & 2.3 \\
AUC 3.5 & $3 / 18$ & 1 & 1 & 2 & 2.4 \\
AUC 4 & $12 / 68$ & $1(8 \%)$ & $8(1 \%)$ & 1 & 3.0 \\
AUC 4.5 & $11 / 63$ & $7(64 \%)$ & $3(25 \%)$ & 11 & 2.9 \\
AUC 5 & $2 / 12$ & $2(100 \%)$ & 6 & 2.7 \\
\hline
\end{tabular}

${ }^{a}$ AUC, area under the plasma concentration time curve (in $\mathrm{mg} \times \mathrm{min} / \mathrm{ml}$ ).

${ }^{b}$ Dose intensity calculated over 8 weeks.

Table 5 Demographics of patients sampled for pharmacologic analysis $(n=14)^{a}$

\begin{tabular}{lcc}
\hline & Median & Range \\
\hline Baseline screening & & \\
Age, years & 56 & $42-66$ \\
BSA, m ${ }^{2 b}$ & 1.95 & $1.78-2.18$ \\
Height, cm & 177 & $169-187$ \\
Weight, kg & 80 & $65-99$ \\
Pretherapy hematology & & \\
Hematocrit, liter/liter & 0.40 & $0.36-0.46$ \\
Leukocytes, $\times 10^{9} /$ liter & 9.0 & $5.0-15$ \\
Neutrophils, $\times 10^{9} /$ liter & 6.2 & $3.2-13$ \\
Pretherapy clinical chemistry & & \\
AST, units/liter & 25 & $12-38$ \\
ALT, units/liter & 24 & $12-38$ \\
ALP, units/liter & 105 & $72-160$ \\
GGT, units/liter & 70 & $19-208$ \\
Total serum bilirubin, $\mu$ mol/liter & 8 & $4-14$ \\
Serum creatinine, $\mu$ mol/liter & 71 & $52-82$ \\
\hline
\end{tabular}

${ }^{a} n$, total number of patients studied.

${ }^{b}$ BSA, body surface area; AST, aspartate amino-transferase; ALT, alanine aminotransferase; ALP, alkaline phosphatase; GGT, $\gamma$-glutamyltransferase. mean values of $0.611 \pm 0.108$ versus $0.69 \pm 0.219 \mu \mathrm{M} \times \mathrm{h}$, respectively [mean difference $( \pm \mathrm{SE}), 0.078 \pm 0.105 ; 95 \%$ confidence limits, -0.151 and $0.308 ; P=0.47$ ]. Likewise, the AUC of total paclitaxel was similar in both groups, with mean values of $7.6 \pm 1.47$ versus $6.96 \pm 1.04 \mu \mathrm{M} \times \mathrm{h}$, respectively [mean difference $( \pm \mathrm{SE}), 0.63 \pm 0.75 ; 95 \%$ confidence limits, -1 and 2.26; $P=0.42$ ]. The absolute clearance of unbound paclitaxel was also not significantly different from historical data obtained in 15 patients treated with single-agent paclitaxel as a 1 -h infusion at $100 \mathrm{mg} / \mathrm{m}^{2}(P=0.52$; Ref. 23$)$.

Cremophor EL concentrations in plasma from 1 patient remained undetectable beyond $8 \mathrm{~h}$ after the end of infusion; this was not the result of technical errors but of interindividual pharmacokinetics of Cremophor EL. Pharmacokinetic parameters for this patient are not listed in Table 7. Disappearance of Cremophor EL from the plasma compartment was characterized by elimination in an apparent biexponential manner, with a mean overall clearance of $123 \pm 23 \mathrm{ml} / \mathrm{h} / \mathrm{m}^{2}$. The AUC of Cremophor EL was similar to that reported in patients treated with paclitaxel in the absence of carboplatin coadministration $[70.5 \pm 16.4$ (range, 54.6-107) versus $80.2 \pm 24.2$ (range, 46.3-123) $\mu \mathrm{l} \times \mathrm{h} / \mathrm{ml} ; P=0.21$; Ref. 23].
Response and Survival. Thirty-seven patients were evaluable for response. All these patients had bidimensionally measurable disease. One patient with a tumor in the proximal esophagus and supraclavicular lymph node metastasis achieved a complete response. This patient received additional radiation therapy to a total dose of 50 gray, and he is alive without evidence of disease after a follow-up of 19 months. A partial response was observed in 19 patients $(51 \%)$. The median duration of partial and complete responses was 9 months (range, 5-30 months). Ten patients had stable disease, and 7 patients had progressive disease. The overall response rate was $54 \%$. Two responding patients with adenocarcinomas of the distal esophagus and celiac lymph node metastases underwent an esophageal resection after chemotherapy. Both patients had radical resections and are currently alive without evidence of disease after a follow-up of 18 and 16 months, respectively. Eleven patients with a partial response after chemotherapy and 4 patients with stable disease received additional treatment with chemotherapy. The median survival for all 40 patients was 11 months (range, 3-30 months), with a 1-year survival rate of $46 \%$.

Table 6 Summary of paclitaxel pharmacokinetic parameters $(n=14)^{a, b}$

\begin{tabular}{|c|c|c|}
\hline Parameter & Mean $\pm \mathrm{SD}$ & Range \\
\hline Paclitaxel dose, mg & $195 \pm 12.7$ & $178-216$ \\
\hline Infusion duration, $\mathrm{h}$ & $1.05 \pm 0.10$ & $1.00-1.38$ \\
\hline \multicolumn{3}{|l|}{ Unbound paclitaxel } \\
\hline $\mathrm{C}_{\max }, \mu \mathrm{M}^{c}$ & $0.349 \pm 0.121$ & $0.231-0.696$ \\
\hline AUC, $\mu \mathrm{M} \times \mathrm{h}$ & $0.662 \pm 0.186$ & $0.425-1.18$ \\
\hline $\mathrm{CL}$, liter $/ \mathrm{h} / \mathrm{m}^{2}$ & $188 \pm 44.6$ & $99.6-276$ \\
\hline $\mathrm{V}_{\mathrm{ss}}$, liter $/ \mathrm{m}^{2}$ & $1250 \pm 661$ & $649-3210$ \\
\hline $\mathrm{T}_{1 / 2, \mathrm{z}}, \mathrm{h}$ & $9.69 \pm 4.91$ & $5.55-25.7$ \\
\hline $\mathrm{AUC}_{\mu} / \mathrm{AUC}_{\rho}, \%$ & $8.9 \pm 1.1$ & $7.6-12$ \\
\hline \multicolumn{3}{|l|}{ Total paclitaxel } \\
\hline $\mathrm{C}_{\max }, \mu \mathrm{M}$ & $3.98 \pm 1.07$ & $2.95-7.04$ \\
\hline $\mathrm{AUC}, \mu \mathrm{M} \times \mathrm{h}$ & $7.37 \pm 1.33$ & $5.60-10.2$ \\
\hline $\mathrm{T}_{1 / 2, \mathrm{z}}, \mathrm{h}$ & $8.84 \pm 1.79$ & $7.09-13.53$ \\
\hline
\end{tabular}

${ }^{a}$ All patients received paclitaxel as a 1-h infusion at a dose of 100 $\mathrm{mg} / \mathrm{m}^{2}$ followed by carboplatin at a dose targeting an AUC of $4 \mathrm{mg} \times$ $\mathrm{min} / \mathrm{ml}(n=5)$ or AUC of $4.5 \mathrm{mg} \times \mathrm{min} / \mathrm{ml}(n=9)$. Data were calculated using a three-compartment model.

${ }^{b} n$, total number of patients studied.

${ }^{c} \mathrm{C}_{\text {max }}$, peak plasma concentration; AUC, area under the plasma concentration time curve; $\mathrm{CL}$, plasma clearance; $\mathrm{V}_{\mathrm{ss}}$, volume of distribution at steady state; $\mathrm{T}_{1 / 2,7}$, half-life of the terminal disposition phase; $\mathrm{AUC}_{\mu} / \mathrm{AUC}_{\rho}$, ratio of unbound to total drug on the basis of AUC. 
Table 7 Summary of cremophor EL pharmacokinetic parameters $(n=13)^{a, b}$

\begin{tabular}{lcc}
\hline \multicolumn{1}{c}{ Parameter } & Mean $\pm \mathrm{SD}$ & Range \\
\hline Cremophor EL dose, $\mathrm{ml}$ & $16.4 \pm 1.04$ & $14.8-18.0$ \\
Infusion duration, $\mathrm{h}$ & $1.02 \pm 0.03$ & $1.00-1.08$ \\
$\mathrm{C}_{\max }, \mu \mathrm{l} / \mathrm{ml}^{c}$ & $2.67 \pm 0.33$ & $2.06-3.15$ \\
$\mathrm{AUC}, \mu \mathrm{l} \times \mathrm{h} / \mathrm{ml}$ & $70.5 \pm 16.4$ & $54.6-107$ \\
$\mathrm{CL}, \mathrm{ml} / \mathrm{h} / \mathrm{m}^{2}$ & $123 \pm 23.0$ & $78.1-153$ \\
$\mathrm{~V}_{\mathrm{ss}}, \mathrm{liter} / \mathrm{m}^{2}$ & $4.49 \pm 0.54$ & $3.71-5.56$ \\
$\mathrm{~T}_{1 / 2, \mathrm{z}}, \mathrm{h}$ & $27.1 \pm 8.06$ & $19.9-50.3$ \\
\hline
\end{tabular}

${ }^{a}$ All patients received paclitaxel as a 1-h infusion at a dose of 100 $\mathrm{mg} / \mathrm{m}^{2}$, followed by carboplatin at a dose targeting an AUC of $4 \mathrm{mg} \times$ $\mathrm{min} / \mathrm{ml}(n=5)$ or AUC of $4.5 \mathrm{mg} \times \mathrm{min} / \mathrm{ml}(n=8)$. Data were calculated using noncompartmental analysis.

${ }^{b} n$, total number of patients studied.

${ }^{c} \mathrm{C}_{\text {max }}$, peak plasma concentration; AUC, area under the plasma concentration time curve extrapolated to infinity; CL, plasma clearance; $\mathrm{V}_{\mathrm{ss}}$, volume of distribution at steady state; $\mathrm{T}_{1 / 2, \mathrm{z}}$, half-life of the terminal disposition phase.

\section{DISCUSSION}

Chemotherapy with or without radiotherapy is frequently used in the treatment of patients with resectable esophageal cancer. Although the outcome of trials reported previously is contradictory, a recently reported large study on preoperative chemotherapy demonstrated a significant survival benefit (24). The role of chemotherapy as palliative treatment for patients with recurrent or metastatic disease has been less well established. In one randomized study, patients with advanced disease were randomized between treatment with cisplatin and 5-fluorouracil or cisplatin alone (25). The higher response rate in the cisplatin/5-fluorouracil arm (37 versus 18\%) did not translate in an improved survival, most likely because $16 \%$ treatment-related deaths were observed in the cisplatin/5-fluorouracil arm compared with $0 \%$ in the cisplatin arm. In other randomized studies, patients with esophageal and gastric cancer are both included, so it is difficult to draw conclusions $(26,27)$.

In this Phase I study, we treated patients with metastatic esophageal cancer with paclitaxel $100 \mathrm{mg} / \mathrm{m}^{2}$ in combination with escalating doses of carboplatin administered on days 1, 8, 15, 29, 36, and 43. At carboplatin dose level AUC 5, the MTD was reached and consisted of a treatment delay of $\geq 2$ weeks on day 29 . The highest dose intensity was achieved at carboplatin dose level AUC 4 , and therefore, we recommend this dose level for additional studies. In general, this weekly schedule of carboplatin and paclitaxel was both well tolerated and convenient to administer in the outpatient setting. Although neutropenia grade 3 or 4 occurred in $77 \%$ of the patients, only 2 patients $(5 \%)$ developed neutropenic fever. Therefore, we consider the myelotoxicity to be acceptable. Other toxicities were either absent or mild.

Sehouli et al. (28) recently reported on a Phase I study in which patients with ovarian cancer untreated previously were treated with a weekly combination of $100 \mathrm{mg} / \mathrm{m}^{2}$ paclitaxel (1-h infusion) and escalating doses of carboplatin. Patients were treated for six consecutive weeks, followed by a 2-week break and another 6 weekly courses. Myelotoxicity was dose limiting at carboplatin dose levels $>$ AUC 2. The difference in MTD between this and our study might be explained by the fact that we treated our patients for three consecutive weeks followed by a 1-week break. After a 1-week break, myelotoxicity recovered in almost all patients treated at the recommended dose level. In addition, we administered only 6 weekly cycles, and the MTD for carboplatin could be lower for 12 cycles because of cumulative myelotoxicity or neurotoxicity.

The achieved dose intensity calculated over 8 weeks at the recommended dose level of carboplatin AUC 3/week and paclitaxel $75 \mathrm{mg} / \mathrm{m}^{2} /$ week is high in comparison with other schedules of carboplatin administered either as a single agent or in combination with paclitaxel. In patients with ovarian cancer untreated previously, the MTD for four cycles of carboplatin as single agent was AUC 12 when carboplatin was administered every 4 weeks (29) and AUC 7 when carboplatin was administered every 2 weeks with the use of granulocyte colony-stimulating factor (30), however, at the cost of severe thrombocytopenia. In combination with $225 \mathrm{mg} / \mathrm{m}^{2}$ paclitaxel, the MTD for carboplatin was AUC 8 in a 3-weekly schedule, however, also at the cost of considerable toxicity.

In previous clinical trials, it has been demonstrated that concurrent carboplatin does not change the disposition of paclitaxel after 3-h infusions $(31,32)$. Likewise, a number of reports documented unaltered pharmacokinetics of carboplatin attributable to pretreatment with paclitaxel at standard doses used in 3-weekly regimens $(33,34)$. Our current study adds to that knowledge by demonstrating that carboplatin also does not modulate paclitaxel disposition after shorter infusions. We also tested the hypothesis that carboplatin might alter the extent of paclitaxel protein binding but found no effect on the fraction unbound paclitaxel relative to historical control data (23). In line with several independent studies (reviewed in Ref. 35), we noted that therapy-associated thrombocytopenia was less than expected in patients treated with the combination of paclitaxel and carboplatin. In the absence of a pharmacokinetic interaction, the reason for this phenomenon is still unclear, although several possible explanations have been invoked. Experimental studies have shown an antagonistic interaction between the two drugs in the megakaryoblast cell line MEG-01 as a model of a platelet precursor (36), which may involve induced production of hematopoietic cytokines, including thrombopoietin, possibly combined with gluthatione S-transferase-mediated detoxification of carboplatin (37). Alternatively, we have recently shown that Cremophor EL, at concentrations achieved in the patients in the current study, acts as a protector for cisplatin-associated hematological side effects in both mice and cancer patients (38), presumably by modulation of accessory factors regulating hematopoietic progenitor cells through the operation of cytokine cascades (39). Further studied beyond the scope of this trial will be required to fully elucidate the mechanisms underlying the platelet-sparing effect of the paclitaxel-carboplatin combination.

The overall response rate of $54 \%$ observed in this Phase I study is high also in view of the fact that almost half of the patients had liver metastases. Because this regimen can be administered over a short period of time, it is also attractive to explore its activity as induction treatment or as part of a combined modality treatment.

In conclusion, carboplatin targeted at AUC 4 in combination with $100 \mathrm{mg} / \mathrm{m}^{2}$ paclitaxel administered on days $1,8,15$, 29,36 , and 43 is the recommended dose for untreated patients with advanced esophageal cancer. Both the observed response rate and toxicity profile compare favorable with other cisplatin- 
based chemotherapy regimens used for patients with esophageal cancer, and in addition to this, this regimen can be administered in an outpatient setting, hereby improving patient convenience for this specific group of patients. Currently, the recommended schedule is further examined in a randomized Phase III study in patients with advanced ovarian cancer.

\section{REFERENCES}

1. Blot WJ, McLaughlin JK. The changing epidemiology of esophageal cancer. Semin Oncol 1999;26(Suppl 15):2-8.

2. Chow WH, Blot WJ, Vaughan TL, et al. Body mass index and risk of adenocarcinoma on the esophagus and gastric cardia. J Natl Cancer Inst (Bethesda) 1998;90:150-5.

3. Lagergren J, Bergstrom R, Lindgren A, Nyren O. Symptomatic gastroesophageal reflux as a risk factor for esophageal adenocarcinoma. N Engl J Med 1999;340:825-31.

4. Jankowski J, Wright NA, Meltzer S, et al. Molecular evolution of the metaplasia dysplasia adenoma sequence in the esophagus (MCS). Am J Pathol 1999;154:965-74.

5. Enzinger PC, Ilson DH, Kelsen DP. Chemotherapy in esophageal cancer. Semin Oncol 1999;26:12-20.

6. Enzinger PC, Kulke MH, Clark JW, et al. Phase II trial of irinotecan in previously untreated patients with advanced adenocarcinoma of the esophagus and stomach (abstract). Proc Am Soc Clin Oncol 2000;19:315.

7. Ilson D, Saltz L, Enzinger P, et al. A phase II trial of weekly irinotecan plus cisplatin in advanced esophageal cancer. J Clin Oncol 1999;17:3270-5.

8. Ilson DH, Ajani J, Bhalla K, et al. Phase II trial of paclitaxel, fluorouracil, and cisplatin in patients with advanced carcinoma of the esophagus. J Clin Oncol 1998;16:1826-34.

9. Ilson DH, Forastiere A, Arquette M, et al. Phase II trial of paclitaxel and cisplatin in patients with advanced carcinoma of the esophagus. Cancer J 2000;6:316-23.

10. Van der Gaast A, Kok TC, Kerkhofs L, Siersema PD, Tilanus HW, Splinter TAW. Phase I study of a biweekly schedule of a fixed dose of cisplatin with increasing doses of paclitaxel in patients with advanced esophageal cancer. Br J Cancer 1999;80:1052-7.

11. Polee MB, Eskens FALM, van der Burg MEL, et al. Phase II study of a biweekly schedule of cisplatin and paclitaxel in patients with advanced esophageal cancer Br J Cancer 2002;86:669-73.

12. Polee MB, Verweij J, Siersema PD, et al. Phase I study of a weekly schedule of a fixed dose of cisplatin and escalating doses of paclitaxel in patients with advanced esophageal cancer Eur J Cancer 2002;38:1495-500.

13. Fennely D, Aghajanian C, Shapiro F, et al. Phase I and pharmacologic study of paclitaxel administered weekly in patients with relapsed ovarian cancer. J Clin Oncol 1997;15:187-92.

14. Akerley W, Glantz M, Choy H, et al. Phase I trial of weekly paclitaxel in advanced lung cancer. J Clin Oncol 1998;16:153-8.

15. Perez EA, Vogel CL, Irwin DH, et al. Multicenter phase II trial of weekly paclitaxel in women with metastatic breast cancer. J Clin Oncol 2001;19:4216-23.

16. Seidman AD, Hudis CA, Albanel J, et al. Dose-dense therapy with weekly 1-hour paclitaxel infusions in the treatment of metastatic breast cancer. J Clin Oncol 1998;16:3353-61.

17. Belani CP. Interim analysis of a phase II study of induction weekly paclitaxel/carboplatin regimens followed by maintenance weekly paclitaxel for advanced and metastatic non-small cell lung cancer. Semin Oncol 2001;28(Suppl 14):14-8.

18. WHO. WHO handbook for reporting results of cancer treatment. WHO Offset Publ. No. 4. Geneva: WHO; 1979.

19. Calvert AH, Newell DR, Gumbrell LA, et al. Carboplatin dosage: prospective evaluation of a simple formula based on renal function. J Clin Oncol 1989;7:1748-56.

20. Sparreboom A, De Bruijn P, Nooter K, Loos WJ, Stoter G, Verweij J. Determination of paclitaxel in human plasma using single solvent extraction prior to isocratic reversed-phase high-performance liquid chromatography with ultraviolet detection. J Chromatogr B 1998;705:159-64.

21. Brouwer E, Verweij J, De Bruijn P, et al. Measurement of fraction unbound paclitaxel in human plasma. Drug Metab Dispos 2000;28:1141-5. 22. Brouwer E, Verweij J, Hauns B, et al. Linearized colorimetric assay for Cremophor EL: application to pharmacokinetics after 1-hour paclitaxel infusions. Anal Biochem 1998;261:198-202.

23. Gelderblom H, Mross K, ten Tije AJ, et al. Comparative pharmacokinetics of unbound paclitaxel during 1- and 3-hour infusions. J Clin Oncol. 2002;20:574-81.

24. Medical Research Council Esophageal Cancer Working Party. Surgical resection with or without preoperative chemotherapy in esophageal cancer: a randomized trial. Lancet 2002;359:1727-33.

25. Bleiberg H, Conroy T, Paillot B, et al. Randomised phase II study of cisplatin and 5-fluorouracil (5-FU) versus cisplatin alone in advanced squamous cell oesophageal cancer Eur J Cancer 1997;33:1216-20.

26. Webb A, Cunningham D, Scarffe JH, et al. A randomized trial comparing ECF with FAMTX in advanced esophagastric cancer. J Clin Oncol 1997; 15:261-7.

27. Vanhoefer E, Rougier P, Wilke H, et al. Final results of a randomized phase III trial of sequential high dose methothrexate, fluorouracil and doxorubicin versus etoposide, leucovorin and fluorouracil versus infusional fluorouracil and cisplatin in advanced gastric cancer; a trial of the European Organization for Research and Treatment of Cancer gastrointestinal tract cooperative group. J Clin Oncol 2001;18:2648-57.

28. Sehouli J, Stengel D, Elling D, et al. First-line chemotherapy with weekly paclitaxel and carboplatin for advanced ovarian cancer: a phase I study. Gynecol Oncol 2002;85:321-6.

29. Gore M, Mainwarring P, A'Hern R, et al. Randomized trial of dose-intensity with single agent carboplatin in patients with epithelial ovarian cancer. London Gynaecological Oncology Group. J Clin Oncol 1998; 16:2426-34.

30. Lind MJ, Ghazal-Aswad S, Gumbrell L, et al. Phase I study of pharmacologically based dosing of carboplatin with filgastrim support in women with epithelial ovarian cancer. J Clin Oncol 1996;14:800-5. 31. Aisner J, Belani CP, Kearns C, et al. Feasibility and pharmacokinetics of paclitaxel, carboplatin, and concurrent radiotherapy for regionally advanced squamous cell carcinoma of the head and neck and for regionally advanced non-small cell lung cancer. Semin Oncol 1995; 5(Suppl 12):17-21.

32. Siddiqui N, Boddy AV, Thomas HD, et al. Clinical and pharmacokinetic study of the combination of carboplatin and paclitaxel for epithelial ovarian cancer. Br J Cancer 1997;75:287-94.

33. Obasaju CK, Johnson SW, Rogatko A, et al. Evaluation of carboplatin pharmacokinetics in the absence and presence of paclitaxel. Clin Cancer Res 1996;2:549-52.

34. Fujiwara K, Yamauchi H, Suzuki S, et al. The platelet-sparing effect of paclitaxel is not related to changes in the pharmacokinetics of carboplatin. Cancer Chemother Pharmacol 2001;47:22-6.

35. Kearns CM, Egorin MJ. Considerations regarding the less-thanexpected thrombocytopenia encountered with combination paclitaxel/ carboplatin chemotherapy. Semin Oncol 1997;1(Suppl 2):S2-91-6.

36. Guminski AD, Harnett PR, deFazio A. Carboplatin and paclitaxel interact antagonistically in a megakaryoblast cell line-a potential mechanism for paclitaxel-mediated sparing of carboplatin-induced thrombocytopenia. Cancer Chemother Pharmacol 2001;48:229-34.

37. Pertussine E, Ratajczak J, Majka M, et al. Investigating the plateletsparing mechanism of paclitaxel/carboplatin combination chemotherapy. Blood 2001;97:638-44.

38. Gelderblom H, Loos WJ, Verweij J, et al. Modulation of cisplatin pharmacodynamics by Cremophor EL: experimental and clinical studies. Eur J Cancer 2002;38:205-13.

39. Bertoncello I, Krieger AB, Woodcock DM, et al. Haematopoietic radioprotection by Cremophor EL: a poly ethoxylated castor oil. Int J Radiat Biol 1995;67:57-64. 